\title{
Kinetics for Camel (Camelus dromedarius) Retina Acetylcholinesterase Inhibition by Methotrexate In Vitro
}

\author{
Abdulaziz A. Al-Jafari, Fareeda Al-Khwyter, Mohammad A. Kamal and Abdullah S. Alhomida \\ Department of Biochemistry, College of Science, King Saud University, P.O. Box 2455, Riyadh 1145I, Saudi Arabia \\ Received May 20, 1996 Accepted June 25, 1996
}

\begin{abstract}
This work addresses the kinetic analysis of the interaction of methotrexate (MTX) with camel retina acetylcholinesterase ( $\mathrm{AChE}, \mathrm{EC}$ 3.1.1.7). It was found that the MTX effect was reversible in nature. The $\mathrm{IC}_{50}$ was determined, by two methods, to be $1.362 \mathrm{mM}$. The Michaelis-Menten constant $\left(\mathrm{K}_{\mathrm{s}}\right)$ for the hydrolysis of acetylthiocholine iodide (ASCh) by AChE was $0.123 \mathrm{mM}$ in the control system, and the MTX-treated systems showed a $10-35 \%$ decrease in this value. The $V_{\max }$ was $0.789 \mu \mathrm{mol} / \mathrm{min} / \mathrm{mg}$ protein for the control system, while it was decreased by $23-76 \%$ in the MTX-treated systems. The LineweaverBurk plot, Dixon plot and their secondary replots indicated that the inhibition was a linear mixed type; i.e., uncompetitive and noncompetitive. The values of $K_{i}$ and $K_{I}$ were estimated as 0.782 and $0.404 \mathrm{mM}$, respectively. The use of camel retina as a model for the study of human retina may open new avenues for studying various aspects of $\mathrm{AChE}$.
\end{abstract}

Keywords: Acetylcholinesterase, Kinetics, Inhibition, Methotrexate, Retina

In the central nervous system (CNS), acetylcholinesterase (acetylcholine hydrolase, EC 3.1.1.7, AChE) is a very efficient enzyme because it hydrolyzes neurotransmitter acetylcholine ( $\mathrm{ACh}$ ) at a rate nearly as fast as allowed by diffusion (1). Cholinesterases are also present in non-cholinergic contexts. For example, AChE and butyrylcholinesterase (EC 3.1.1.8, BChE) are found in the early stages embryonic development, well before the apparition of cholinergic synapses (2). Therefore, AChE and $\mathrm{BChE}$ could be involved in the formation or regulation of $\mathrm{ACh}$ gradients that could guide the growth of nerve cells (3). AChE is also present at the surface of the red cells of some vertebrates or in soluble form in the plasma, together with $\mathrm{BChE}(4,5)$. In blood, AChE and $\mathrm{BChE}$ are thought to play a detoxification role (6). The presence of $\mathrm{AChE}$ and $\mathrm{ACh}$ in vertebrate retina have been extensively documented $(7,8)$. The functional role of $\mathrm{ACh}$ in visual transmission in all mammalian retinas has been fairly well-documented $(9-12)$. Also there is a wealth of data demonstrating the effect of cholinergic drugs and anticholinesterases on the function of the retinas (13). The effects reported by various groups of investigators appear to vary widely. Inhibition of $\mathrm{AChE}$ has been reported to either hasten or reduce the process of dark adaptation $(14-16)$. Thus, although decreases in visual activity have often been noted following exposure to anticholinesterases and a muscarinic cholinergic agonist, which may cause an increase in the flicker fusion frequency $(17,18)$, these effects have largely been ascribed to changes in accommodative ability (19).

Although the retina is embryologically derived from the CNS and rich in AChE, the interactions of $\mathrm{AChE}$ with various inhibitors have not been investigated in this tissue, especially in camel retina $(7,20)$. We believe that camel retina may be an ideal model for studying various aspects of human AChE such as the pharmacokinetic effects of various drugs and chemicals, because it has the specific characteristics of a centrally elongated macular area in which mainly cone photoreceptors are found. Moreover, there is no tapetum lucidum layer between the choroid and retina as found in the eyes of large nocturnal mammals (21).

A series of studies on the effect of anticancer drugs on $\mathrm{AChE}$ activities has begun in our laboratory (22-26). One of the studied drugs is methotrexate (4-amino-10-methylpteroyl-glutamate, MTX), which has been widely used in the treatment of neoplastic disease $(27,28)$ rheumatoid arthritis (29) and psoriasis (30), as well as for the treatment of intraocular lymphoma (31). However, its therapeutic use is affected by various types of neurotoxicity following treatment with MTX. Some of the reported examples of MTX neurotoxicity are: acute transient 
cerebral dysfunction (32), death of nerve cells in the brain stem (33) and degeneration of the autonomic nerve fibers in the small intestine (34). Severe toxicity on retina resulted as evaluated by electroretinography (35). A survey of the literature reveals that many, if not all, anticancer drugs can inhibit different enzymes in vitro and in vivo $(22-24,36,37)$. However, little is known about the inhibitory effect of MTX on retinal AChE.

It was of interest, therefore, to gain more insight into the mechanism of retina AChE inhibition by MTX in vitro. To this end, a study was carried out with a camel retina detergent soluble enzyme. In this study, we report the sensitivity of the enzyme to this anti-neoplastic drug, which manifests some of its side effects on the CNS.

\section{MATERIALS AND METHODS}

\section{Materials}

Acetylthiocholine iodide (ASCh, used as substrate), 5,5'-dithiobis-(2-nitro) benzoic acid (DTNB), MTX, adenine and citrate-phosphate-dextrose solution were purchased from Sigma Chemical Co. (St. Louis, MO, USA), and bovine serum albumin (BSA) was obtained from Fluka Chemika-BioChemika, (Buchs, Switzerland). All other chemicals were of the highest grade available from commercial sources.

\section{Methods}

Enzyme preparation: Retinas of young camels (Camelus dromedarius) were obtained from the local abattoir. The whole retina from each eye was rapidly removed, rinsed in pre-cold $0.9 \%$ saline solution, blotted and weighed. In each batch of enzyme preparation, twenty whole retinas were prepared by homogenizing them in pre-chilled $50 \mathrm{mM}$ sodium phosphate buffer. The homogenization and centrifugation processes for the extraction of retina membrane-bound $\mathrm{AChE}$ by $0.5 \%$ Triton $\mathrm{X}-100$ were performed as described in the previous report (38).

Assay of AChE activity: AChE activity was determined by the spectrophotometric method of Ellman et al. (39). The 4-min incubation time was selected for the enzyme assay, after preliminary experiments were performed to ensure that the enzyme activity was linear with respect to the reaction time and enzyme concentration employed (8).

To study the effect of MTX, the enzyme was preincubated with MTX for 4 min prior to the addition of substrate. The $; \mathrm{K}_{\mathrm{s}}$ represents the dissociation constant of the AChE-ASCh-MTX complex into the AChE-MTX complex and ASCh. The inhibition constant $K_{I}$ represents the dissociation constant of the AChE-ASCh-MTX complex into the AChE-ASCh complex and free MTX.
Dialysis: A solution of AChE $(150 \mu)$ and MTX (1.5 $\mathrm{mM}, 2100 \mu \mathrm{l})$ was prepared in $4060 \mu \mathrm{l} 50 \mathrm{mM}$ sodium phosphate buffer ( $\mathrm{pH} 7.4$ ). A $1.0-\mathrm{ml}$ aliquot was assayed by addition of ASCh and DTNB ( $n=3)$, and the remaining $3310 \mu \mathrm{l}$ was dialyzed against $700 \mathrm{ml}$ buffer at $8^{\circ} \mathrm{C}$ for $20 \mathrm{hr}$. A control solution (AChE and buffer only) was treated similarly.

Protein estimation: The protein content of the enzyme preparation was estimated according to the method of Lowry et al. (40) using BSA as a standard. The detergent Triton X-100 interfered with this assay, so the precipitate was removed by centrifugation as described previously

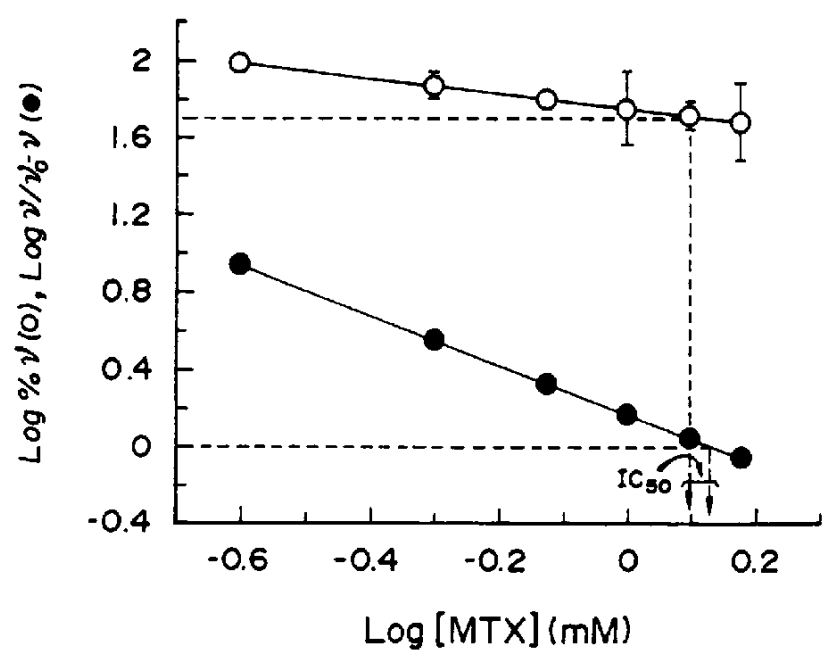

Fig. 1. Camel retina AChE inhibition as a function of MTX concentration. The data are presented in two ways: i) $\log \left(v / v_{0}-v\right)(\mathrm{O})$, where $y$ and $v_{0}$ are the reaction rates for the experimental and control systems, respectively; ii) $\log \%$ residual activity of $\mathrm{AChE}(\bigcirc)$ was plotted versus log MTX concentration. The correlation coefficient was 0.9502 and 0.8723 for $\log \left(v / v_{0}-v\right)$ and $\log \%$ residual activity of AChE plots, respectively. Each point represents the mean \pm S.D. of four determinations of triple batches of the enzyme preparation.

Table 1. Effect of MTX on kinetic parameters of camel retina AChE

\begin{tabular}{rrrrr}
\hline $\begin{array}{r}\text { MTX } \\
(\mathrm{mM})\end{array}$ & $\begin{array}{r}\mathrm{K}_{\text {sapp }} \\
(\mathrm{mM})\end{array}$ & $\%$ Decrease & $\begin{array}{r}\mathrm{V}_{\text {maxap }} \\
(\mathrm{U} / \mathrm{mg})\end{array}$ & \% Decrease \\
\hline 0.00 & $\mathbf{0 . 1 1 5}$ & 0.00 & 0.671 & 0.00 \\
0.25 & $\mathbf{0 . 1 0 3}$ & 10.43 & 0.518 & 22.80 \\
0.50 & 0.095 & 17.22 & 0.397 & 40.84 \\
1.00 & 0.084 & 27.04 & 0.253 & 62.30 \\
1.50 & 0.075 & 34.96 & 0.160 & 76.11 \\
\hline
\end{tabular}

The $\mathrm{K}_{\mathrm{sapp}}$ and $\mathrm{V}_{\text {maxapp }}$ were determined by their respective regression equation as well as by the Lineweaver-Burk plot (Fig. 2A). The $K_{\text {sapp }}$ is equal to the reciprocal of the $x$-intercept and $V_{\text {maxapp }}$ is equal to the reciprocal of $y$-intercept of each line for each MTX concentration in the Lineweaver-Burk plot (each point in this figure represents the mean of four determinations of triple batches of the enzyme preparation). 
(41).

Statistical analyses: The graphs were plotted by the Grafitter program (42). The values of the correlation coefficient, slope, intercept and their standard errors were obtained by the linear regression analysis of this program.
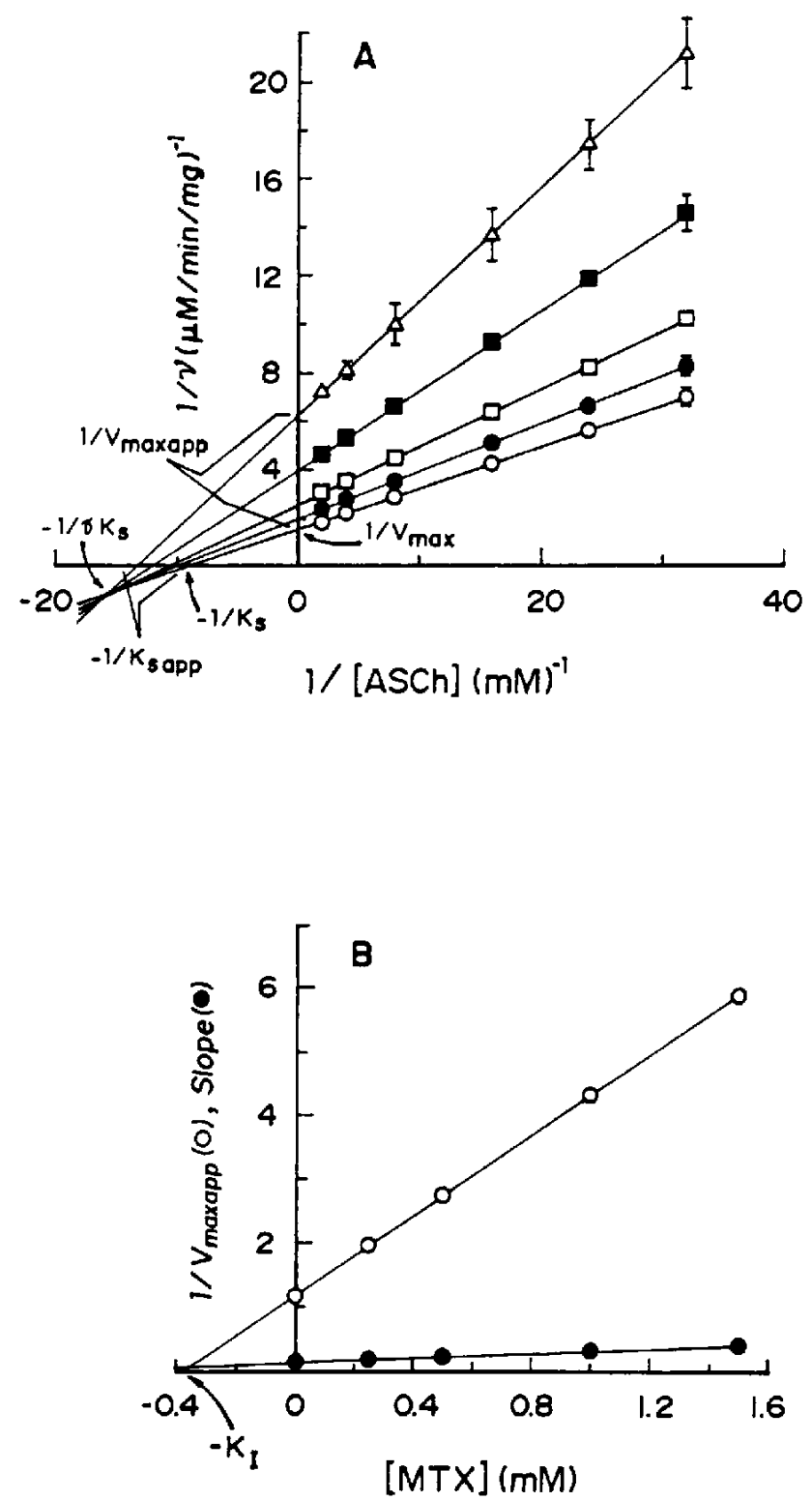

Fig. 2. Inhibition of camel retina AChE by MTX. A: LineweaverBurk plot of $1 /$, against $1 / \mathrm{ASCh}$ in the absence $(\bigcirc)$ and presence of $0.25 \mathrm{mM}(\bigcirc), 0.50 \mathrm{mM}(\rceil), 1.0 \mathrm{mM}(\square)$ and $1.50 \mathrm{mM}(\triangle) \mathrm{MTX}$. Each point represents the mean \pm S.D. of four determinations of triple batches of the enzyme preparation. B: Secondary replot of $1 / \mathrm{V}_{\operatorname{maxapp}}(\mathrm{O})$ and slope (O) from the Lineweaver-Burk plot against MTX concentration for the determination of $K_{1}$ and $K_{i}$, respectively. The correlation coefficient was 0.9862 and 0.9899 for replot of $1 / \mathrm{V}_{\text {maxapp }}$ and slope, respectively.

\section{RESULTS}

Dialysis data show that $57.88 \pm 1.48 \%$ of the AChE activity was restored (before dialysis, the activity of the AChE-MTX solution was $16.71 \pm 0.25 \%$ of the control,
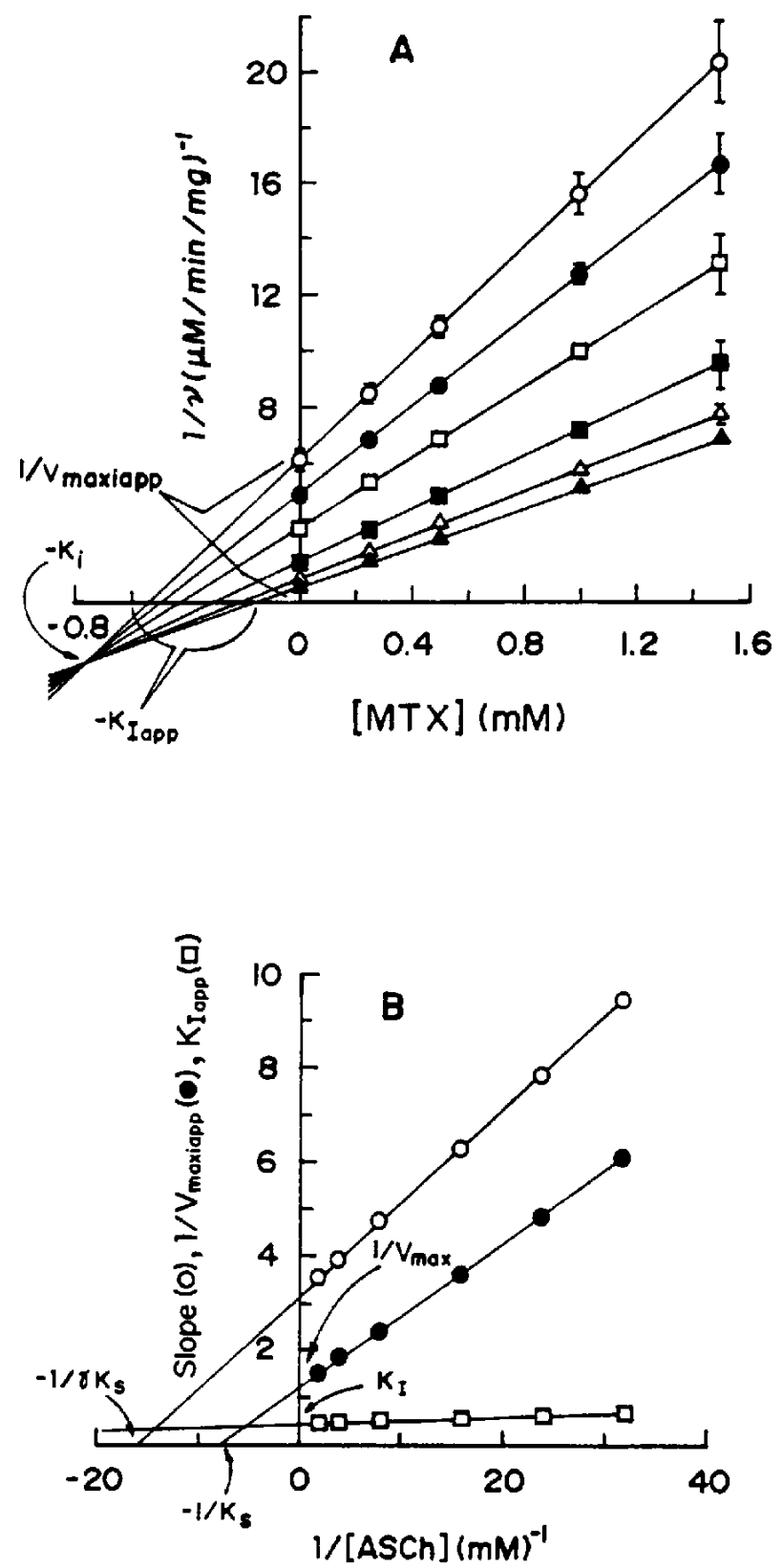

Fig. 3. Inhibition of camel retina AChE by MTX. A: Dixon plot for representation at six different fixed concentrations of $0.50 \mathrm{mM}$ $(\Delta), 0.25 \mathrm{mM}(\triangle), 0.125 \mathrm{mM}(\square), 0.0625 \mathrm{mM}(\square), 0.042 \mathrm{mM}(\mathbf{O})$ and $0.031 \mathrm{mM}(\bigcirc)$ ASCh in the presence of 0-1.50 mM MTX. Each point represents the mean \pm S.D. of four determinations of triple batches of the enzyme preparation. B: Secondary replot of slope $(\bigcirc), 1 / \mathrm{V}_{\text {maxiapp }}(\mathrm{O})$ and $\mathrm{K}_{\text {lapp }}(\square$ ) from the Dixon plot against 1/[ASCh]. The correlation coefficient was 1,1 and 0.9728 for the replot of slope, $1 / \mathrm{V}_{\text {maxiapp }}$ and $\mathrm{K}_{\text {lapp }}$, respectively. 
while after dialysis, the corresponding value was $74.59 \pm 1.13 \%, \mathrm{n}=3$ ).

The transformed data, $\log \left(\nu / \nu_{0}-1\right)$ for the $\mathrm{AChE}$ inhibition as a function of $\log$ MTX concentration, is presented in Fig. 1 for the estimation of $\mathrm{IC}_{50}$. The results show that MTX $(0.25-1.50 \mathrm{mM})$ inhibits AChE activity $(11.7-61.4 \%)$ in a concentration dependent manner, with $\mathrm{IC}_{50}$ being about $1.349 \mathrm{mM}$. The $\mathrm{IC}_{50}$ was also determined by plotting $\log \%$ residual activity verses $\log$ [MTX] concentration, which gave a value of $1.374 \mathrm{mM}$. The mean $\mathrm{IC}_{50}$ obtained by the above two methods was $1.362 \pm 0.0125 \mathrm{mM}$.

The data in Table 1 shows that MTX $(0-1.50 \mathrm{mM})$

Table 2. Kinetic constants estimated by various methods

\begin{tabular}{lccccc}
\hline Method & $\begin{array}{c}\mathrm{K}_{\mathrm{i}} \\
(\mathrm{mM})\end{array}$ & $\begin{array}{c}\mathrm{K}_{\mathrm{I}} \\
(\mathrm{mM})\end{array}$ & $\begin{array}{c}\mathrm{K}_{\mathrm{s}} \\
(\mathrm{mM})\end{array}$ & $\begin{array}{c}\mathrm{K}_{\mathrm{s}} \\
(\mathrm{mM})\end{array}$ & $\begin{array}{c}\mathrm{V}_{\max } \\
(\mathrm{U} / \mathrm{mg})\end{array}$ \\
\hline Primary plot & 0.784 & - & 0.115 & 0.061 & 0.671 \\
Secondary replot $^{1 \mathrm{LBP}}$ & - & 0.375 & - & - & 0.848 \\
Secondary replot $^{2 \mathrm{LBP}}$ & 0.779 & - & - & - & - \\
Secondary replot $^{\mathrm{IDP}}$ & - & - & - & 0.0626 & - \\
Secondary replot $^{2 \mathrm{DP}}$ & - & - & 0.130 & - & 0.848 \\
Secondary replot $^{3 \mathrm{DP}}$ & - & 0.433 & - & - & - \\
Mean value & 0.782 & 0.404 & 0.123 & 0.062 & 0.789 \\
S.E.M. & 0.0025 & 0.0291 & 0.0076 & 0.001 & 0.0591 \\
\hline
\end{tabular}

The details of the primary plot and secondary replots are given in the text; ${ }^{\text {LBP }}$ means Lineweaver-Burk plot and ${ }^{D P}$ means Dixon plot. ${ }^{1 L B P}$ represents the replot of $1 / V_{\text {maxapp }}$ versus MTX concentration and ${ }^{2 \mathrm{LBP}}$ represents the replot of the slope from the Lineweaver-Burk plot versus MTX concentration (Fig. 2B). ${ }^{1 D P}$ represents the replot of the slope from the Dixon plot versus ASCh concentration, 2DP represents the replot of $1 / V_{\text {maxiapp }}$ versus $A S C h$ concentration and ${ }^{3 D P}$ represents the replot of $K_{\text {lapp }}$ from the Dixon plot versus ASCh concentration (Fig, 3B).

Table 3. Kinetic data from Dixon plot for camel retina $\mathrm{AChE}$ inhibition by MTX

\begin{tabular}{ccccc}
\hline $\begin{array}{c}\text { ASCh } \\
(\mathrm{mM})\end{array}$ & $\begin{array}{c}\mathrm{K}_{\text {lapp }} \\
(\mathrm{mM})\end{array}$ & \% Decrease & $\begin{array}{c}\mathrm{V}_{\text {maxiap }} \\
(\mathrm{U} / \mathrm{mg})\end{array}$ & \% Increase \\
\hline 0.031 & 0.646 & - & 0.164 & - \\
0.042 & 0.617 & 4.49 & 0.206 & 25.61 \\
0.063 & 0.576 & 10.84 & 0.276 & 68.29 \\
0.125 & 0.504 & 21.98 & 0.418 & 154.88 \\
0.250 & 0.463 & 28.33 & 0.550 & 235.37 \\
0.500 & 0.420 & 34.99 & 0.673 & 310.37 \\
\hline
\end{tabular}

The $K_{\text {Iapp }}$ and $V_{\text {maxiapp }}$ were determined by their respective regression equation and Dixon plot (Fig. $3 \mathrm{~A}$ ). The $\mathrm{K}_{\text {lapp }}$ is equal to the $\mathrm{x}$-intercept and $V_{\text {maxiapp }}$ is equal to reciprocal of the y-intercept of each line for each ASCh concentration in the Dixon plot (each point in this figure represents the mean of four determinations of triple batches of the enzyme preparation). decreases $\mathrm{K}_{\mathrm{m}}(10.43-34.96 \%)$ and $\mathrm{V}_{\max }(22.8-76.11 \%)$. The type of inhibition produced by MTX was assessed by a Lineweaver-Burk plot as well as a Dixon plot. As shown in Figs. 2A and 3A, MTX inhibited AChE activity as a mixed-type inhibitor. This linear mixed-type inhibition system is considered to be composed of uncompetitive and pure noncompetitive-type inhibitions.

The $K_{\mathrm{s}}$ and $\gamma \mathrm{K}_{\mathrm{s}}$ values of the camel retina AChE were found to be $0.123 \pm 0.008$ and $0.062 \pm 0.001 \mathrm{mM}$, respectively. These values were calculated from the mean of the primary double reciprocal plot (Fig. 2A), regression equations and secondary replot of the 1/slope (for $\gamma K_{s}$ ), $1 / \mathrm{V}_{\text {maxiapp }}\left(\right.$ for $\mathrm{K}_{\mathrm{s}}$ ) from a Dixon plot, against the reciprocal form of ASCh concentration (Fig. 3B). The values for these kinetic parameters such as $\mathrm{K}_{\mathrm{i}}, \mathrm{K}_{\mathrm{l}}, \mathrm{K}_{\mathrm{s}}, \gamma \mathrm{K}_{\mathrm{s}}$ and $\mathrm{V}_{\max }$ calculated by these three methods are summarized in Table 2. The $\mathrm{K}_{\text {lapp }}$ for each ASCh concentration was estimated by a regression equation and is presented in Table 3. The $\mathrm{K}_{\text {Iapp }}$ decreased from $4.49-34.99 \%$ and $\mathrm{V}_{\text {maxiapp }}$ increased between $25.61 \%$ and $310.37 \%$ over the range of ASCh concentration used. The values of $K_{i}$ and $K_{I}$ were calculated from primary Dixon plots and secondary replots (43a) of slope and $1 / \mathrm{V}_{\text {maxapp }}$ values from the Lineweaver-Burk plot (Fig. 2B) and regression equation for each ASCh concentration at fixed MTX concentration in the Dixon plot.

\section{DISCUSSION}

The restoration of AChE activity $(57.88 \pm 1.48 \%$ ) by dialysis suggests that the MTX effect is reversible (44). The $\mathrm{IC}_{50}$ of camel retina $\mathrm{AChE}$ for MTX was 1.9 times more than that of the human erythrocyte enzyme, showing that the inhibitory potency of MTX is lower in camel retina than human AChE (Table 4).

The patterns of the lines in the Lineweaver-Burk plot (Fig. 3A) did not follow the patterns expected for simple intersecting linear inhibition systems; i.e., competitive,

Table 4. Comparative data for the effect of MTX on human erythrocyte* and camel retina $\mathrm{AChE}$

\begin{tabular}{lcc}
\hline Parameter & Human* & Camel \\
\hline $\mathrm{K}_{\mathrm{s}}(\mathrm{mM})$ & 0.13 & 0.123 \\
$\gamma \mathrm{K}_{\mathrm{s}}(\mathrm{mM})$ & 0.026 & 0.062 \\
$\mathrm{~V}_{\max }(\mathrm{U} / \mathrm{mg})$ & 1.27 & 0.789 \\
$\mathrm{IC}$ & 0.73 & 1.362 \\
$\mathrm{~K}_{\mathrm{i}}(\mathrm{mM})$ & 1.67 & 0.782 \\
$\mathrm{~K}_{\mathrm{I}}(\mathrm{mM})$ & 0.34 & 0.404 \\
Mode of inhibi- & mixed (uncompetitive & mixed (uncompetitive \\
tion & +noncompetitive) & +noncompetitive) \\
\hline
\end{tabular}

${ }^{*}$ Reference 48. 
noncompetitive and uncompetitive. Therefore, this means that the inhibition of camel retina AChE by MTX is a mixed-type inhibition. In the case of mixed-type inhibition, there are two types: partial and linear. These two types can be distinguished on the basis of the shape of the Dixon plots; A curved plot indicates a partial mixed-type inhibition system. In our case, the Dixon plot was linear (Fig. 3A), indicating that our system exhibited linear mixed-type inhibition. The linear mixed-type inhibition system can be further categorized into two main types: in the first type, $\alpha>1$, where the family of Dixon plots as well as Lineweaver-Burk plots intersect above the horizontal axis, while in the second case, $\alpha<1$, where the family of straight lines (control and "plus inhibitor") in the Lineweaver-Burk as well as Dixon plots intersect below the $\mathrm{X}$-axis. In the present study we found the latter case; i.e., intersection below the $\mathrm{X}$-axis, indicating a mixed-type system showing both uncompetitive and noncompetitive types of inhibition.

The uncompetitive type has also two subtypes: partial and pure. Our system is the pure one, because the plot of $1 / 1$-axis intercept (i.e., $1 / \mathrm{V}_{\text {maxapp }}$ ) versus [MTX] was linear (Fig. 2B), instead of hyperbolic as in the case of partial uncompetitive inhibition (43b).

As in uncompetitive type of inhibition, the noncompetitive type of inhibition has also two subtypes: partial and pure, which can be distinguished on the basis of replots of slope $\mathrm{I}_{1 / \mathrm{ASCh}}$ and $1 / \mathrm{V}_{\text {maxapp }}$ versus [MTX]. In this study we found linear (Fig. 2B) plots that indicate pure noncompetitive inhibition, instead of hyperbolic, as in the case of the partial noncompetitive subtype. There is still one point that requires clarification: in the case of pure competitive inhibition, the slope $\mathrm{I}_{1 / \mathrm{ASCh}}$ plot should also be a linear function of inhibitor concentration (43c) which was observed here; however, this is, overcome by the secondary replot of the Dixon plot, i.e., slope versus $1 /$ [ASCh], in which the straight line does not pass through the origin as it does with a replot in the case of pure competitive inhibition (Fig. 3B).

The results indicate that MTX might produce a conformational change of the enzyme by binding with the AChE-ASCh complex reversibly, yielding a non-productive AChE-ASCh-MTX complex. In this way, MTX can decrease the activity of the enzyme because it can prevent the proper positioning of the catalytic center for acylation with substrate to form acylated $\mathrm{AChE}$ due to steric hindrance; i.e., peripheral binding of MTX might decrease acylation to a greater extent than deacylation $(\gamma=0.504)$. MTX decreases the $V_{\max }$, and $K_{\text {sapp }}$, although not to the same extent as in pure uncompetitive inhibition, as is very clearly observable from the pattern of the secondary plots in Fig. 2B. Moreover, MTX and ASCh are not mutually exclusive and both can bind independently of each other to free AChE, as well as the AChE-ASCh or AChE-MTX complex.

The decrease in $K_{\text {sapp }}$ values indicates that MTX increases the substrate affinity towards the anionic site of the active center (45). However, the decrease in $\mathbf{K}_{\text {sapp }}$ value with MTX occurred because the reaction (AChEASCh + MTX $\rightarrow$ AChE-ASCh-MTX) removes some of the AChE-ASCh complex, thereby causing the reaction $(\mathrm{AChE}+\mathrm{ASCh} \rightarrow \mathrm{AChE}-\mathrm{ASCh})$ to proceed to the right.

The decrease in $V_{\text {maxapp }}$ of the enzyme on increasing MTX concentration can be explained in two ways. One possibility is the indirect interaction of MTX on the esteratic site through van der Waals volumes of aromatic residues of the active-site gorge of $\mathrm{AChE}$ at the free stage of $\mathrm{AChE}$, due to the noncompetitive component. This effect causes deformation of the esteratic site or disturbance in the quaternary structure of this site in such a way that proper catalysis will be hindered (or reduced). The second possibility for decreasing $V_{\text {maxapp }}$ is that MTX binds with the peripheral anionic site (at AChE-ASCh stage) in such a way that it induces a wave of disturbance in all types of binding forces, resulting in conformational changes in the esteratic site at the active center of the $\mathrm{AChE}$ and thus block the deacylation process. The uncompetitive component is responsible for this latter type of inhibition pattern.

According to the accepted hydrolysis scheme for acetate substrate by AChE (46), MTX can also interact with $\mathrm{AChE}$ at either the AChE-ASCh complex stage or the AAChE stage. The former possibility is more probable, because if MTX was bound to A-AChE, $P_{1}$ would not be affected, while the results show that $P_{1}$ is affected by increasing the concentration of MTX, because absorption of the color product was decreased at $412 \mathrm{~nm}$. This means that MTX did not bind with A-AChE and bound instead with the AChE-ASCh complex. Now, considering the case of the AChE-ASCh complex, the anionic site is occupied by the cholinic part of the ASCh and thus is not available to a second ligand. Therefore MTX must bind with a peripheral anionic site. The low value of the $\mathrm{K}_{\mathrm{I}} / \mathrm{K}_{\mathrm{i}}$ ratio $(\alpha=0.517)$ suggests that MTX has greater affinity towards the peripheral site than the van der Waals volumes of aromatic residues of the esteratic site (47). The comparative data for the effect of MTX on human erythrocyte (48) and camel retina AChE are presented in Table 4. From these results, it can be concluded that the MTX has a mixed-type inhibitory effect on camel retina AChE. If AChE is inhibited by MTX in vivo, neurotransmitter $\mathrm{ACh}$ will accumulate in the synapses and neuromuscular junctions, which will interfere with the regular sequence of the nerve impulses and, ultimately, muscle contraction and loss of normal function will appear. The mechanism of action of MTX on camel retina AChE 
resembles its interaction with human erythrocyte $\mathrm{AChE}$ (48). On the basis of the present kinetic parameters such as $K_{i}, K_{I}, \gamma K_{s}, K_{s}, V_{\max }$ and the nature of the inhibition (Table 4), our hypothesis that camel retina can be used as an ideal model has been proven.

\section{REFERENCES}

1 Quinn DM: Acetylcholinesterase: enzyme structure, reaction dynamics, and virtual transition states. Chem Rev 87, 955-979 (1987)

2 Drews U: Cholinesrerase in embryonic development. Prog Histochem Cytochem 7, 1-52 (1975)

3 Layer PG, Alber $\mathbf{R}$ and Rathjen FG: Sequential activation of butyrylcholinesterase in rostral half somites and acetylcholinesterase in motoneurones and myotomes preceding growth of motor axons. Development 102, 387-396 (1988)

4 Taylor $P$ and Radic Z: The cholinesterases: from genes to proteins. Annu Rev Pharmacol Toxicol 34, 281 - 320 (1994)

5 Al-Jafari AA: Investigation of the reversible inhibition of camel (Camelus dromedarius) acetylcholinesterase by tetracaine. Comp Biochem Physiol 105C, 323-327 (1993)

6 Neville LF, Gnatt A, Loewenstein Y and Soreq H: Aspartate-70 to glycine substitution confers resistance to naturally occurring and synthetic anionic-site ligands on in-ovo produced human butyrylcholinesterase. J Neurosci Res 27, 452-460 (1990)

7 Jen LS, Tsang D, Chau RMW and Shen WZ: The cholinergic system in retinal transplants in rats. Brain Res 523, 156-160 (1990)

8 Al-Khwyter F, Kamal MA and Al-Jafari AA: The inhibitory effect of cyclophosphamide on camel retina acetylcholinesterase. Toxicol Lett (in press)

9 Masland RH and Mills JW: Autoradiographic identification of acetylcholine in the rabbit retina. J Cell Biol 83, 159-178 (1979)

10 Millar TJ, Ishimoto I, Chubb IW, Epstein ML and Johnson CD: Cholinergic amacrine cells of the chicken retina: a light and electron microscope immunocytochemical study. Neuroscience 21, 725- 742 (1987)

11 Pourcho RG and Osman K: Acetylcholinesterase localization in cat retina: a comparison with choline acetyltransferase. Exp Eye Res 43, 585-594 (1986)

12 Ross CD, Dunning DD, Juengel LI and Godfrey DA: Laminar distribution of choline acetyltransferase and acetylcholinesterase activities in the inner plexiform layer of rat retina. J Neurochem 44, 1091 - 1099 (1985)

13 Rengstorff $\mathrm{R}$ and Royston M: Miotic drugs: a review of ocular, visual, and systemic complications. Am J Optom Physiol Opt 53, 70-80 (1976)

14 Trussov MS: Effects of eserine upon light sensitivity and dark adaptation. Oftalmol $\mathrm{Zh} \mathrm{17,366-371} \mathrm{(1962)} \mathrm{[Translation} \mathrm{of}$ Rengstorff RH and Gurvis V: Am J Optom Physiol Opt 52, 438-444 (1975)]

15 Rubin LS and Goldberg MN: Effect of sarin on dark adaptation in man: threshold changes. J Appl Physiol 11, $439-444$ (1957)

16 Rubin LS, Krop S and Goldberg MN: Effect of sarin on dark adaptation in man: mechanism of action. J Appl Physiol 11, 445-449 (1957)

17 Fleming K: Über die Wirkung sympathicolytischer und parasympathicolytischer Pharmaka auf die Flimmerverschmel- zungssgrenze. [On the action of sympathetolytic and parasympathetolytic drugs on the flicker fusion frequency]. Arch Exp Pathol Pharmacol 230, 328 - 334 (1957) (in German)

18 Alpern $M$ and Jampel RS: The effects of autonomic drugs on human ficker discrimination. Am J Ophthalmol 47, 464-476 (1959)

19 Hutchins JB, Bernanke JM and Jefferson VE: Acetylcholinesterase in developing ferret retina. Exp Eye Res 60, 113125 (1995)

20 Hutchins JB: Acetylcholinesterase as a neurotransmitter in the vertebrate retina. Exp Eye Res 45, 1-38 (1987)

21 Duhaiman AS: Purification and some properties of camel lens crystallins. Curr Eye Res 7, 871-876 (1988)

22 Al-Jafari AA: The toxicological effect of cyclophosphamide on acetylcholinesterase activity. Toxicol Lett 66, 125-131 (1993)

23 Al-Jafari AA, Duhaiman AS and Kamal MA; Inhibition of human acetylcholinesterase by cyclophosphamide. Toxicology 96, 1-6 (1995)

24 Al-Jafari AA, Kamal MA and Duhaiman AS: The mode of inhibition of human erythrocyte membrane-bound acetylcholinesterase by cisplatin in vitro. J Enz Inhibit 8, 281-289 (1995)

25 Kamal MA and Al-Jafari AA: Estimation and correlation of $\mathrm{IC}_{50}$ with time for the inhibition of human erythrocyte acetylcholinesterase by cisplatin. Cell Pharm 3, 45-48 (1996)

26 Al-Jafari AA: Kinetics for the inhibition of acetylcholinesterase from human erythrocyte by eisplatin. Int $\mathrm{J}$ Biochem Cell Biol 27, $965-970$ (1995)

27 Bertino JR: Toward improved selectivity in cancer chemotherapy: the Richard and Hinda Rosenthal Foundation Award Lecture. Cancer Res 39, 293- 304 (1979)

28 Avella M, Bacci G, Mcdonald DJ, Discioscio M, Picci P and Campanacci $M$ : Adjuvant chemotherapy with six drugs (adriamycin, methotrexate, cisplatinum, bleomycin, cyclophosphamide and dactinomycin) for non-metastatic, highgrade osteosarcoma of the extremities. Chemotherapia 7, 133- 137 (1988)

29 Weinblatt ME, Coblyn JS, Fox DA, Fraser PA, Holdsworth $D E$, Glass DN and Trentham DE: Efficacy of low-dose methotrexate in rheumatoid arthritis. $\mathrm{N}$ Engl $\mathrm{J}$ Med 312, 818-822 (1985)

30 Rees RB, Bennt JR, Maibach HI and Arnold HL: Methotrexate for psoriasis. Arch Dermatol 95, 2-11 (1967)

31 Valluri S, Moorthy RS, Khan A and Rao NA: Combination treatment of intraocular lymphoma. Retina 15, 125-129 (1995)

32 Allen JC and Rosen G: Transient cerebral dysfunction following chemotherapy for osteogenic sarcoma. Ann Neurol 3, $441-444$ (1978)

33 Haddara MA, El-Badawi $\mathbf{M G}$, Fatani JA, Ibrahim $\mathbf{M}$ and Dahaha NM: Neuronal death after i.p. injection of methotrexate in young mice. Al-Azher Med J 14, 25-30 (1985)

34 El-Badawi MG, Fatani JA and Qayyum MA: Methotrexate neurotoxicity - a histochemical study. Anat Anz 164, 47-52 (1987)

35 Vernot J, Peyman GA, Gailitis R, Fiscella R, Woodhouse M and Weinberg D: Effects of selected repeated intravitreal chemotherapeutic agents. Int Opthalmol 8, 193-198 (1985)

36 Leblanc GA and Waxman DJ: Interaction of anticancer drugs with hepatic monooxygenase. Drug Metab Rev 20, 395-439 (1989) 
37 Sadzuka Y, Shoji $T$ and Takino Y: Effect of cisplatin on the activities of enzymes which protect against lipid peroxidation. Biochem Pharmacol 43, 1872-1875 (1992)

38 Al-Jafari AA: The nature of the inhibition of camel retina acetylcholinesterase (EC 3.1.1.7) activity by tetrahydroaminoacridine. J Ocul Pharmacol Ther (in press)

39 Ellman GL, Courtney D, Andres V and Featherston RM: A new and rapid colorimetric determination of acetylcholinesterase activity. Biochem Pharmacol 7, 88-95 (1961)

40 Lowry $\mathrm{OH}$, Rosebrough NJ, Farr AL and Randall RJ: Protein measurement with the Folin phenol reagent. J Biol Chem 193, 265-275 (1953)

41 Al-Jafari AA and Kamal MA: Optimization and kinetic studies of human erythrocyte membrane-bound acetylcholinesterase. Biochem Mol Biol Int 38, 579- 588 (1996)

42 Leatherbarrow RJ: GraFit.Version 3.0, Erithacus Software Ltd., Staines (UK) (1992)

43 Segel IH: Enzyme Kinetics: Behavior and Analysis of Rapid Equilibrium and Steady-State Enzyme Systems. $a=p p 172$
$-176, b=p p 183-185, c=p p 108-111$, John Wiley and Sons, New York (1975)

44 Dawson R: Reversibility of the inhibition of acetylcholinesterase by tacrine. Neurosci Lett 11, $85-87$ (1990)

45 Goldenberg GJ, Vanstone $C L$ and Bihler I: Transport of nitrogen mustard on the transport-carrier for choline in L5178Y lymphoblasts. Science 172, 1148-1149 (1971)

46 Cohen SG, Chishti SB, Bell DA, Howard SI, Salih E and Cohen JB: General occurence of binding to acetylcholinesterase-substrate complex in noncompetitive inhibition and in inhibition by substrate. Biochim Biophys Acta 1076, 112-122 (1991)

47 Hallak $M$ and Szinicz L: Effects of some mono- and bisquaternary ammonium compounds on the reactivatability of somaninhibited human acetylcholinesterase in vitro. Biochem Pharmacol 37, 819-825 (1988)

48 Kamal MA, Nasim FH and Al-Jafari AA: In vitro inhibition of human erythrocyte acetylcholinesterase (EC 3.1.1.7) by an antineoplastic drug methotrexate. Mol Cell Biochem 159, 47-53 (1996) 